\title{
Rhodiola Crenulata ameliorates exhaustive exercise-induced fatigue in mice by suppressing mitophagy in skeletal muscle
}

\author{
YA HOU $^{1}$, YAN TANG ${ }^{1}$, XIAOBO WANG $^{1}$, XIAOPENG AI $^{1}$, HONGLING WANG $^{2}$, XUANHAO LI $^{1}$, \\ XIAORUI CHEN ${ }^{1}$, YI ZHANG ${ }^{2}$, YAO HU ${ }^{3}$, XIANLI MENG ${ }^{4}$ and JING ZHANG $^{2}$ \\ ${ }^{1}$ Department of Pharmacology of Chinese Materia Medica, School of Pharmacy; \\ ${ }^{2}$ Ethnic Medicine Academic Heritage Innovation Research Center; ${ }^{3}$ Interdisciplinary Laboratory of Exercise and Medicine; \\ ${ }^{4}$ Innovative Institute of Chinese Medicine and Pharmacy, Chengdu University of Traditional Chinese Medicine, \\ Chengdu, Sichuan 611137, P.R. China
}

Received September 29, 2019; Accepted May 20, 2020

DOI: $10.3892 / \mathrm{etm} .2020 .9072$

\begin{abstract}
The aim of present study was to evaluate the potential effects of Rhodiola crenulata oral liquid (RCOL) on exhaustive exercise (EE)-induced fatigue in mice. Male Institute of Cancer Research mice from five treatment groups ( $\mathrm{n}=10$ per group) were orally administered with sterilized water for the Control and EE groups and/or RCOL at doses of 1.02, 3.03 and $6.06 \mathrm{ml} / \mathrm{kg} / \mathrm{day}$, once daily for 2 weeks. Anti-fatigue activity was subsequently evaluated by measuring the levels of creatine kinase (CK), lactic acid (LA), lactate dehydrogenase (LDH), malondialdehyde (MDA), superoxide dismutase (SOD), catalase (CAT) and total anti-oxidative capability (T-AOC). Histopathology was assessed using hematoxylin and eosin staining. Ultrastructures of mitochondria were observed by transmission electron microscopy. Energy supply capacity was assessed using citrate synthase (CS), succinate dehydrogenase ( $\mathrm{SDH}), \mathrm{Na}^{+}-\mathrm{K}^{+}$-ATPase, and liver and quadriceps glycogen content assays. Expression levels of mRNA and protein associated with mitophagy in the skeletal muscle were measured by reverse transcription-quantitative PCR and western blotting, respectively. RCOL was observed to markedly inhibit fatigue-induced oxidative stress by increasing the activities of SOD, CAT and T-AOC, whilst reducing the accumulation of $\mathrm{LA}, \mathrm{CK}, \mathrm{LDH}$ and MDA.
\end{abstract}

Correspondence to: Dr Xianli Meng, Innovative Institute of Chinese Medicine and Pharmacy, Chengdu University of Traditional Chinese Medicine, 1166 Liutai Street, Wenjiang, Chengdu, Sichuan 611137, P.R. China

E-mail:xlm999@cdutcm.edu.cn

Dr Jing Zhang, Ethnic Medicine Academic Heritage Innovation Research Center, Chengdu University of Traditional Chinese Medicine, 1166 Liutai Street, Wenjiang, Chengdu, Sichuan 611137, P.R. China

E-mail: 31649123@qq.com

Key words: Rhodiola crenulata oral liquid, quadriceps femoris, loaded swimming, anti-fatigue, mitophagy
Histological analysis of the quadriceps femoris tissue suggested increased numbers of muscle fibers in the RCOL groups compared with those in the EE group. RCOL administration was found to reverse EE-induced mitochondrial structural damage and alleviated defects inflicted onto the energy supply mechanism by increasing $\mathrm{CS}, \mathrm{SDH}, \mathrm{Na}^{+}-\mathrm{K}^{+}$-ATPase and glycogen levels. Additionally, RCOL reduced the protein expression of PTEN-induced kinase 1 (PINK1), Parkin, microtubule-associated proteins $1 \mathrm{~A} / 1 \mathrm{~B}$ light chain 3 , sequestosome 1 and ubiquitin, whilst lowering the gene expression of PINK1 and Parkin. Taken together, results from the present study clarified the anti-fatigue effect of RCOL, where the underlying mechanism may be associated with increased antioxidant activity, enhanced energy production and the inhibition of mitophagy by suppressing the PINK1/Parkin signaling pathway.

\section{Introduction}

Fatigue is a common condition that is caused by strenuous physical activity and harmful diseases, including grueling exercise (1) and cancer $(2,3)$. Although symptoms of fatigue can be eliminated and relieved by appropriate exercise in many cases (4-6), people of different nationalities, occupations and ages all experience fatigue due to current social pressure, such as work and competitive pressure. If left unchecked, fatigue not only reduces productivity and that quality of life but can also contribute to the progression of fatigue itself.

Mitochondria are important intracellular organelles that produce the adenosine triphosphate (ATP) required for the contraction of skeletal muscles in mammals. Previous studies have demonstrated that muscle mitophagy was associated with metabolic disorders, including obesity and skeletal muscle dyskinesia concomitant with Parkinson's disease $(7,8)$. Long-term and appropriate exercise have been found to increase plasticity and mitochondrial biogenesis in skeletal muscle. Mitochondria in skeletal muscle can also exhibit physiological adaptation from oxygen-dependent aerobic glycolysis to oxidative phosphorylation under anaerobic conditions (9). Skeletal muscles account for $30 \%$ of the body's weight in humans that serve as the storehouse of amino acids and 
carbohydrates, in addition to being the converter of chemical energy into mechanical energy (10). To maintain a satisfactory level of health and quality of life, a sufficient number of mitochondria in skeletal muscles is required. For both professional athletes and the general public, strength building and the maintenance of various types of movement or posture require healthy skeletal muscles (11). Increases in the number of mitochondria can improve the performance of professional athletes and the health of ordinary people. Indeed, a previous study has reported that chronic exercise can drive mitochondria biogenesis and fusion in skeletal muscles of healthy people who trained regularly for an extended period of time after a previously sedentary period (12). Notably, high-intensity exercise can lead to the excess autophagy of skeletal muscle mitochondria, by process by which damaged mitochondria are removed by autophagic lysosomal complexes $(11,13)$. However, a reduction in the number of mitochondria caused by excessive autophagy can lead to skeletal muscle weakness (12). Therefore, understanding the mechanism that lead to exercise-induced mitochondrial dysfunction can provide insights into novel treatment options for fatigue.

Rhodiola crenulata oral liquid (RCOL) is a widely applied agent in traditional Chinese medicine for the treatment of ailments such as altitude sickness and physical weakness (14). Rhodiola crenulata is an endangered species of perennial herbaceous plant from the Crassulaceae family that is distributed mainly in Tibet. In traditional Tibetan herbal medicine, it is believed to increase physical endurance (15-17), to confer anti-fatigue (18) and anti-hypoxia properties (19). Additionally, previous studies have reported that Rhodiola crenulate, specifically its main active ingredient, salidroside, have a diverse range of pharmacological effects, including anti-inflammatory $(20,21)$, neuroprotective (22-24), eyesight protective (25), anti-radiation (26) and anti-cancer activities (27). However, the potential effects of RCOL on exhaustive exercise (EE)-induced fatigue in skeletal muscle remain poorly understood. Therefore, in the present study, an established in vivo mouse model of muscle fatigue was used to investigate the potential anti-fatigue effects of RCOL administration, in addition to the underlying mechanism, specifically mitophagy.

\section{Materials and methods}

Ethical statement. The present study was approved by The Animal Research Ethics Committee of Chengdu University of Traditional Chinese Medicine. All experimental protocols were performed in accordance with The Animal Care Guidelines, conforming to The Health Guide for the Care and Use of Laboratory Animals (28).

Reagents. CommercialRCOL was purchased from Tibet Tibetan Medicine Group Co., Ltd. (authorization no. B20070002). Primary antibodies against PTEN-induced kinase protein 1 (PINK1; cat. no. BC100-494) were purchased from Novus Biologicals, LLC. Antibodies specific for Parkin (cat. no. 2132), ubiquitin (cat. no. 3933), LC3-II/LC3-I (cat. no. 4108), sequestosome 1 (SQSTM 1/p62; cat. no. 5114), citrate synthase (CS, cat. no. 14309), and GAPDH (cat. no. 5174) were obtained from Cell Signaling Technology, Inc.
Lactic acid (LA; cat. no. A019-2), creatine phosphokinase (CK; cat. no. A032), lactic dehydrogenase (LDH; cat. no. A020-1), malondialdehyde (MDA; cat. no. A003-1), superoxide dismutase (SOD; cat. no. A001-2), catalase (CAT; cat. no. A007-1), total anti-oxidative capability (T-AOC; cat. no. A015), succinate dehydrogenase (SDH, cat. no. A022), and $\mathrm{Na}^{+}-\mathrm{K}^{+}$-ATPase (cat. no. A070-2) activity detection kits were purchased from Nanjing Jiancheng Bioengineering Institute. Glycogen content detection kits (cat. no. BC0345) and $2.5 \%$ Gluta transmission electron microscope specimen fixative (cat. no. P1126) were provided by Beijing Solarbio Science \& Technology Co., Ltd. Xylene, acetone, phosphoric acid, osmium acid, uranyl acetate, lead citrate and paraformaldehyde were purchased from Chengdu Chron Chemicals Co., Ltd.

High performance liquid chromatography (HPLC) analysis of gallic acid, salidroside, tyrosol, catechin, caffeic acid and p-coumaric acid in RCOL. To quantify the main constituents in RCOL, gallic acid (cat. no. M-017-181216), salidroside (cat. no. H-040-170403), tyrosol (cat. no. L-042-180426), catechin (cat. no. E-011-180725), caffeic acid (cat. no. K-003-181216) and p-coumaric acid (cat. no. D-032-171216) were used as reference substances (all purchased at $98 \%$ purity from Chengdu Ruifen Si Biotechnology Co., Ltd.). The HPLC protocol was performed as described previously $(22,29)$. Briefly, a mixture of the reference substances $(0.1306 \mathrm{~g} / \mathrm{ml}$ gallic acid, $0.1394 \mathrm{~g} / \mathrm{ml}$ salidroside, $0.0646 \mathrm{~g} / \mathrm{ml}$ tyrosol, $0.0038 \mathrm{~g} / \mathrm{ml}$ catechin, $0.1140 \mathrm{~g} / \mathrm{ml}$ caffeic acid and $0.0222 \mathrm{~g} / \mathrm{ml} \mathrm{p}$-coumaric acid) and RCOL were analyzed using the Agilent 1260 Infinity System (Agilent Technologies, Inc.). The samples were filtered through $0.45-\mu \mathrm{m}$ microporous membranes, following which $10 \mu \mathrm{l}$ of the sample was loaded onto a $\mathrm{C}_{18}$ chromatographic column (Inner diameter x length: 4.6x250 mm; particle size: $5 \mu \mathrm{m}$; cat. no. 5020-39033, Yili Scientific Instrument Co., Ltd.) and separated using an initial mobile phase consisting of $0.2 \%$ phosphoric acid solution and acetonitrile. Gradient elution was then performed using acetonitrile as follows: i) $7 \%$ for $0-8 \mathrm{~min}$; ii) $7-13 \%$ for 8-27 min; iii) $13-15 \%$ for $27-30 \mathrm{~min}$; iv) $15-18 \%$ for $30-45 \mathrm{~min}$; and v) $18 \%$ for $45-70 \mathrm{~min}$ at a column flow rate of $0.5 \mathrm{ml} / \mathrm{min}$ and a temperature of $25^{\circ} \mathrm{C}$. The curve regression equation was obtained by diluting $1.306 \mathrm{mg} / \mathrm{ml}$ gallic acid, $1.394 \mathrm{mg} / \mathrm{ml}$ salidroside, $0.646 \mathrm{mg} / \mathrm{ml}$ tyrosol, $0.222 \mathrm{mg} / \mathrm{ml} \mathrm{p}$-coumaric acid, $1.114 \mathrm{mg} / \mathrm{ml}$ caffeic acid and $0.038 \mathrm{mg} / \mathrm{ml}$ catechin by 2, 4, 8 and 16 times, respectively. Corresponding peaks were determined at a wavelength of $275 \mathrm{~nm}$.

Animals. Male, six-week-old Institute of Cancer Research (ICR) mice $(25 \pm 2 \mathrm{~g})$ were provided by Chengdu Dashuo Experimental Animal Co., Ltd. The license number for the use of experimental animals is SYXK (Chuan) 2013-124. All mice were kept under standard conditions at $23 \pm 2{ }^{\circ} \mathrm{C}$ and 50-60\% humidity, with a 12-h light/dark cycle. Mice with similar mean body weights were randomly divided and housed in groups of five animals per cage. They were provided with free access to standard diet and sterilized water. All animal experiments were approved by The Animal Care Committee of Chengdu University of Traditional Chinese Medicine. 
Loaded swimming test. A total of 50 mice were randomly divided into five experimental groups of ten mice each: i) Control group; ii) Exhaustive exercise group (EE); iii) Low-Dose group (RCOL-L; $1.02 \mathrm{ml} / \mathrm{kg} /$ day); iv) Medium-Dose group (RCOL-M; 3.03 ml/kg/day); and v) High-Dose group (RCOL-H; $6.06 \mathrm{ml} / \mathrm{kg} /$ day). Mice in the three RCOL groups were given ROCL by oral gavage once daily for two weeks. The nutritional information for RCOL is summarized in Table I. Mice in the control and EE groups were given a volume of sterilized water equivalent to the volume of RCOL administered according to the body weight of the mouse.

All mice except for those in the control group first underwent free swimming training without any loads in a single 20-min training session each day for 3 days, after which they were challenged with a loaded swimming test to establish EE-induced damage in the quadriceps, using a procedure previously described (30). Briefly, the swimming test was applied $1 \mathrm{~h}$ after the final dosing, with a lead weight $\sim 5 \%$ of the mouse body weight attached at the base of the tails. All mice were challenged individually under the same conditions (water temperature, $25 \pm 1^{\circ} \mathrm{C}$; depth, $30 \mathrm{~cm}$ ), where failure to come to the water surface for breathing within $10 \mathrm{sec}$ was determined as a sign of exercise fatigue. At the end of the swimming trial, the mice were sacrificed by cervical dislocation. Subsequently, $\sim 0.6 \mathrm{ml}$ blood samples from the eyeball were collected, liver and quadriceps tissues were collected for further experiments. The workflow of the present experimental protocol is shown in Fig. 1.

Measurement of anti-fatigue biomarkers and glycogen synthesis ability in the mouse serum and quadriceps femoris. Serum samples from mice were obtained by centrifugation at $12,000 \times \mathrm{g}$ for $10 \mathrm{~min}$ at $4^{\circ} \mathrm{C}$. Levels of biomarkers associated with fatigue were measured in the serum $(\mathrm{CK})$ or in the quadriceps femoris tissues of the hind legs ( $\mathrm{LA}, \mathrm{LDH}$, MDA, SOD, CAT and T-AOC). Glycogen synthesis ability was assessed by measuring glycogen levels in the liver and quadriceps femoris tissues. In addition, CS, SDH and $\mathrm{Na}^{+}-\mathrm{K}^{+}$-ATPase activities were also measured in quadriceps femoris tissues. All analytes were measured according to the manufacturer's protocols.

Histopathological estimations of quadriceps femoris. A portion of the quadriceps tissue (10x5x5 mm) was carefully dissected from mice in each of the treatment groups and fixed in $4 \%$ formaldehyde overnight at $25^{\circ} \mathrm{C}$. Paraffin blocks were then prepared after dehydration $(75 \%$ ethanol for $6 \mathrm{~h}$, $85 \%$ ethanol for $10 \mathrm{~h}, 95 \%$ ethanol for $4 \mathrm{~h}$, anhydrous ethanol I and II for $2 \mathrm{~h}$ ), clearing (dimethylbenzene xylene I and II for $20 \mathrm{~min}$ and $15 \mathrm{~min}$, respectively) and wax impregnation for $3 \mathrm{~h}$. The blocks were cut then into 5- $\mu \mathrm{m}$ sections using a rotary microtome (RM2235; Leica Microsystems GmbH), deparaffinized in xylene, rehydrated with deionized water at $25^{\circ} \mathrm{C}$ for $20 \mathrm{~min}$ and stained with hematoxylin for $30 \mathrm{~min}$ and eosin for $5 \mathrm{~min}$ at $25^{\circ} \mathrm{C}$. Following the staining protocol, the quadriceps sections from five mice in each group were digitally captured using a bright field light microscope (magnification x200; CX22; Olympus Corporation) equipped with an image capture system (DM1000; Leica Microsystems $\mathrm{GmbH})$. The number of muscle fibers was counted in each
Table I. Composition of Rhodiola crenulata oral liquid.

\begin{tabular}{llcc}
\hline Peak no. & Compound & $\begin{array}{c}\text { Retention } \\
\text { time }(\mathrm{min})\end{array}$ & $\begin{array}{c}\text { Concentration } \\
(\mathrm{mg} / \mathrm{ml})\end{array}$ \\
\hline 1 & Gallic acid & 9.557 & 1.8690 \\
2 & Salidroside & 23.077 & 1.2709 \\
3 & Tyrosol & 27.618 & 0.5359 \\
4 & Catechin & 31.544 & 0.0109 \\
5 & Caffeic acid & 36.232 & 0.0989 \\
6 & p-coumaric acid & 46.943 & 0.4086 \\
\hline
\end{tabular}

sample, where the cross-sectional area of 20 muscle fibers in three random fields was measured using Image-Pro Plus software version 6.0 (Media Cybernetics, Inc.).

Ultrastructural analysis of mitochondria in the quadriceps femoris by transmission electron microscopy (TEM). The quadriceps femoris was dissected further into $1-\mathrm{mm}^{3}$ samples and fixed using a $2.5 \%$ Gluta transmission electron microscope specimen fixative $(\mathrm{pH} 7.2-7.4)$ for $4 \mathrm{~h}$ at $4^{\circ} \mathrm{C}$, following which they were rinsed three times for $15 \mathrm{~min}$ each with $0.1 \mathrm{M}$ phosphate solution. The samples were then fixed at $25^{\circ} \mathrm{C}$ with $1 \%$ osmium acid for $3 \mathrm{~h}$ and then rinsed again three times for $15 \mathrm{~min}$ each with $0.1 \mathrm{M}$ phosphate solution. The samples were then dehydrated at $4^{\circ} \mathrm{C}$, using the following dehydration protocol: i) $50 \%$ ethanol for $15-20 \mathrm{~min}$; ii) $70 \%$ ethanol for $15-20 \mathrm{~min}$; iii) $90 \%$ ethanol for $15-20 \mathrm{~min}$; iv) $90 \%$ ethanol and $90 \%$ acetone (1:1) for $15-20 \mathrm{~min}$; v) $90 \%$ acetone for $15-20 \mathrm{~min}$; and vi) $100 \%$ acetone at room temperature for 15-20 min three times. Embedding and solidification were then performed using SPI-Pon 812 embedding kit (Structure Probe, Inc.) overnight at $37^{\circ} \mathrm{C}$, then for $12 \mathrm{~h}$ at $45^{\circ} \mathrm{C}$ and finally for $24 \mathrm{~h}$ at $60^{\circ} \mathrm{C}$. Ultrathin $50-60-\mathrm{nm}$ sections were then cut using an ultramicrotome (EM UC7; Leica Microsystems GmbH), collected onto copper grids and stained for 5 min with $3 \%$ uranyl acetate and lead citrate at $25^{\circ} \mathrm{C}$. The grids were then washed with distilled water and viewed under a transmission electron microscope (magnification x10,000; JEM1230; JEOL) for the observation of the muscle tissue ultrastructure. A total 10 muscle cells in random non-overlapping fields per grid were considered for counting purposes and five grids were assessed in each group using Image-Pro Plus software version 6.0 (Media Cybernetics, Inc.).

Western blot analysis. The quadriceps femoris of mice were dissected and immediately separated on ice. Tissue homogenate was obtained from the quadriceps femoris tissues using the FastPrep-24 ${ }^{\mathrm{TM}}$ sample preparation system (MP Biomedicals, LLC) as described previously (7,31-33). Total protein was isolated using a whole cell lysis assay (cat. no. KGP2100; Ken Gen Biotech. Co., Ltd.). A BCA protein assay kit (cat. no. AR0146; Boster Biological Technology) was used to evaluate the protein concentration of each sample. Equivalent amounts (40 $\mu \mathrm{g} /$ lane) of protein samples were separated by SDS-PAGE on $10 \%$ gels, following which they were transferred onto $0.45-\mu \mathrm{m}$ PVDF membranes (cat no. IPVH00010, EMD Millipore). The membranes were 


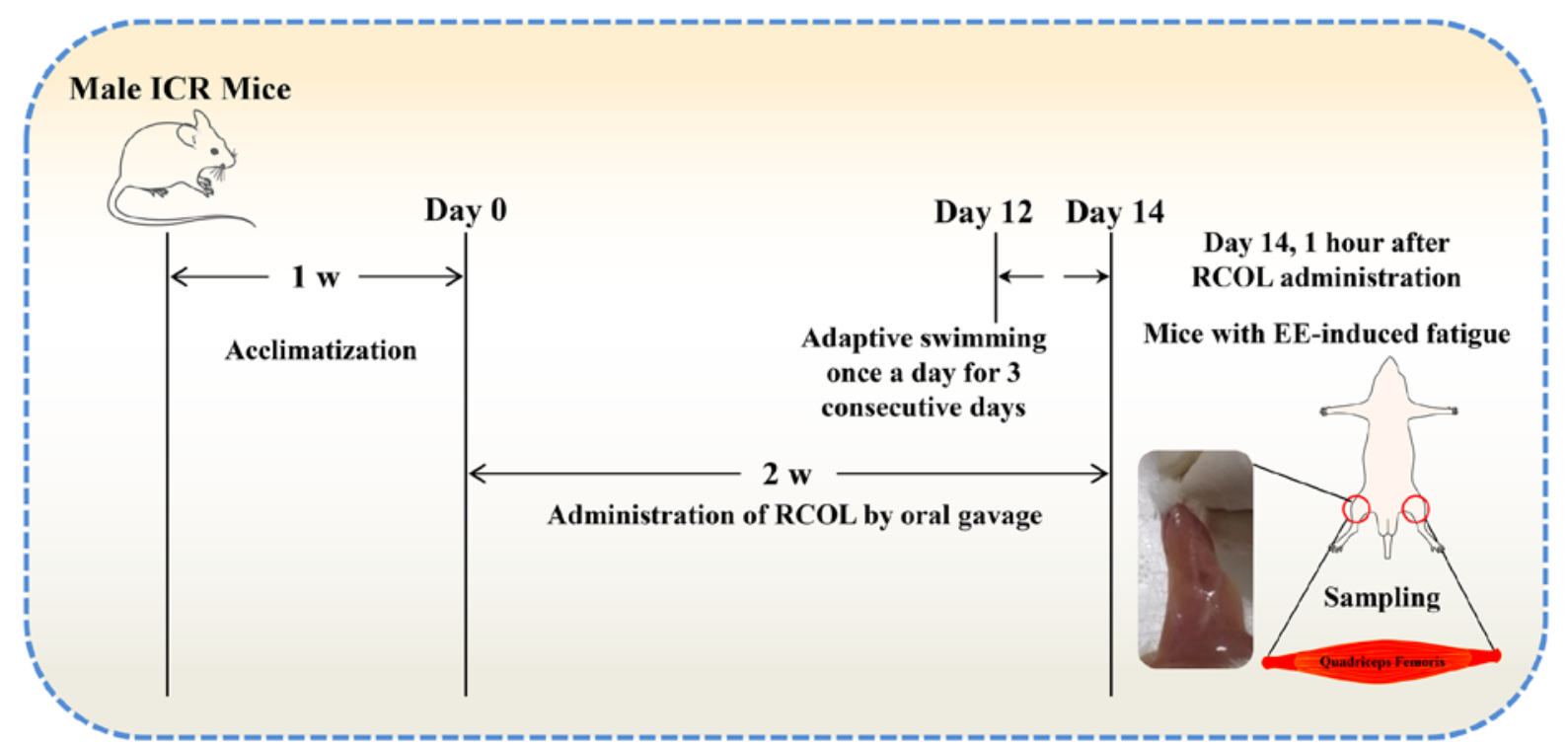

Figure 1. Experimental workflow of the present study. RCOL, Rhodiola crenulata oral liquid; EE, exhaustive exercise; ICR, Institute of Cancer research; $\mathrm{W}$, week.

then blocked with $5 \%$ non-fat milk for $2 \mathrm{~h}$ at $25^{\circ} \mathrm{C}$ and incubated with primary antibodies against CS, PINK1, Parkin, LC3I/II, SQSTM-1/p62, ubiquitin and GAPDH overnight at $4^{\circ} \mathrm{C}$ (all at 1:1,000 dilution). The membranes were then incubated with horseradish peroxidase-conjugated goat anti-rabbit IgG secondary antibody (1:1,000; cat. no. GB23303, Wuhan Servicebio Technology Co., Ltd.) for $2 \mathrm{~h}$ at $25^{\circ} \mathrm{C}$ and washed with PBS containing 0.1\% Tween-20 (cat. no. T8220; Beijing Solarbio Science \& Technology Co., Ltd.) three times for 10 min each. Finally, Ultrasignal ECLelectrochemiluminescent substrate (cat. no. 4AW011-100; Beijing 4A Biotech Co., Ltd.) was used for the visualization of the protein bands and images were captured using ChampChemi 610 Plus (Beijing Sage Creation Science Co., Ltd.). Density values of bands were calculated using Image-Pro Plus software version 6.0 (Media Cybernetics, Inc.) and normalized to GAPDH.

Reverse transcription-quantitative PCR (RT-qPCR). Total RNA was extracted from quadriceps femoris tissue using TRIzol $^{\circledR}$ according to manufacturer's protocol (Invitrogen; Thermo Fisher Scientific, Inc.). cDNA was subsequently synthesized by reverse transcription using a commercial Maxima SYBR Green Real-Time PCR kit (cat. no. KGA1339; Nanjing KeyGen Biotech Co., Ltd.) according to the manufacturer's instructions. RT-qPCR was performed in an ABI 7300 real-time PCR system (Applied Biosystems; Thermo Fisher Scientific, Inc.). All reactions were set up in $20 \mu \mathrm{l}$ volumes using $\mathrm{SYBR}^{\mathrm{TM}}$ Green PCR Master Mix according to manufacturer's protocol (Applied Biosystems; Thermo Fisher Scientific, Inc.). The following thermocycling conditions were used for the qPCR: Initial denaturation at $95^{\circ} \mathrm{C}$ for $30 \mathrm{sec} ; 40$ cycles comprising denaturation at $95^{\circ} \mathrm{C}$ for $5 \mathrm{sec}$, annealing at $60^{\circ} \mathrm{C}$ for $30 \mathrm{sec}$ and elongation at $72^{\circ} \mathrm{C}$ for $30 \mathrm{sec}$; and final extension at $72^{\circ} \mathrm{C}$ for $5 \mathrm{~min}$. PINK1 and Parkin mRNA expression were normalized to those of GAPDH and presented as $2^{-\Delta \Delta \mathrm{Cq}}(34)$. The primer sequences used are listed in Table II.
Statistical analysis. Data are presented as the mean \pm SD. Statistical analysis was performed using SPSS version 21.0 (IBM Corp.). Data were analyzed using one-way ANOVA followed by Tukey's multiple comparison post hoc test. $\mathrm{P}<0.05$ was considered to indicate a statistically significant difference.

\section{Results}

Abundance of the six key compounds contained within RCOL. Detection and quantification of the six active compounds of RCOL (gallic acid, salidroside, tyrosol, p-coumaric acid, caffeic acid, and catechin) were first performed by HPLC. Concentrations were determined using the following curve regression equations: i) Gallic acid, $y=5 \times 10^{7} x+942161$, $r=0.9992$; ii) Salidroside, $y=5 \times 10^{6} x-21828, r=1$; iii) Tyrosol, $y=10^{7} x-19063, r=1$; iv) p-coumaric acid, $y=7 \times 10^{7} x-50372, r=1$; v) Caffeic acid, $y=5 \times 10^{7} x+115424, r=0.9999$, and vi) Catechin, $y=1 \times 10^{7} x-7681.9, r=0.9999$. The relative abundance of the six compounds in RCOL are shown in Fig. 2 and Table I. Among them, the concentration of gallic acid and salidroside is the highest, at 1.8690 and $1.2709 \mathrm{mg} / \mathrm{ml}$, respectively.

Effects of RCOL administration on body weight of mice. The weight of the mice was recorded before and after RCOL treatment. Beyond the naturally increased body weight observed in mice, the continuous administration of RCOL for 14 days had no significant effects on body weight in the mice from each group by the end of the experiment (Table III).

Effects of RCOL administration on the levels offatigue-related biomarkers in serum and quadriceps femoris tissues. After 2 weeks of RCOL pre-administration, the mice underwent 3 days of weight-free adaptive swimming training from day 12 onwards, once per day (Fig. 1). On day 14, $1 \mathrm{~h}$ after RCOL administration, a weight-loaded swimming-induced skeletal muscle fatigue protocol was initiated on the mice, 
Table II. Primers used for reverse transcription-quantitative PCR.

\begin{tabular}{lcl}
\hline Gene & GenBank accession no. & \multicolumn{1}{c}{ Primer sequence, 5'-3' } \\
\hline GAPDH & NM_017008.4 & F, TCACTATTGGCAACGAGCGGTTC \\
PINK1 & NM_026880.2 & R, GCACTGTGTTGGCATAGAGGTCTT \\
Parkin & & F, CAGTGTAGAGCGTGGTGGCAAT \\
& NM_016694.4 & R, AGGCACCGACTCAGGCATCT \\
& & F, GCTTGACACGAGTGGACCTGAG \\
& & R, AACTGGACCTCTGGCTGCTTCT
\end{tabular}

F, forward; R, reverse; PINK1, PTEN-induced kinase 1.
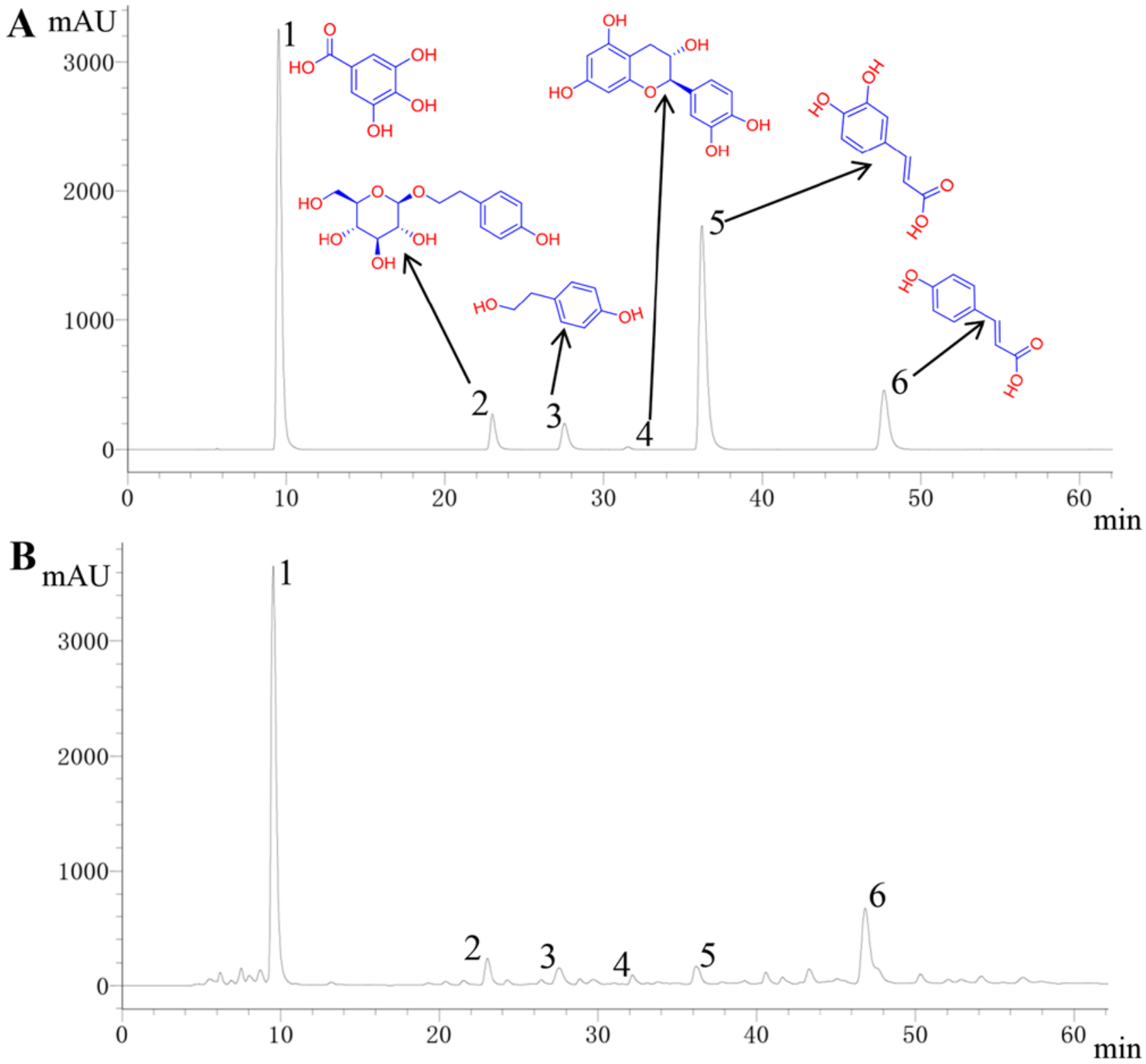

Figure 2. High performance liquid chromatography determination of the six major components contained within RCOL. (A) Chemical structures of the six mixed reference substances. (B) Determination of the relative content of the six main active components of RCOL. 1, gallic acid; 2, salidroside; 3, tyrosol; 4 , catechin; 5 , caffeic acid; 6, p-coumaric acid; RCOL, Rhodiola crenulata oral liquid.

following which serum and quadriceps femoris samples were collected immediately after the end of the trial to detect changes in fatigue-related indicators. Compared with those in the EE group, significantly increased activities of SOD, CAT 
Table III. Effect of RCOL administration on mouse BW.

\begin{tabular}{|c|c|c|c|c|c|}
\hline Title & Control & $\mathrm{EE}$ & RCOL-L & RCOL-M & RCOL-H \\
\hline Initial BW (g) & $27.93 \pm 1.19$ & $28.27 \pm 0.92$ & $28.14 \pm 1.21$ & $27.77 \pm 0.86$ & $27.55 \pm 0.99$ \\
\hline Final BW (g) & $35.50 \pm 2.11$ & $35.85 \pm 1.22$ & $35.25 \pm 1.75$ & $32.24 \pm 2.11$ & $31.28 \pm 1.44$ \\
\hline$\Delta \mathrm{BW}(\mathrm{g})$ & $7.50 \pm 1.70$ & $7.60 \pm 0.93$ & $7.10 \pm 1.72$ & $4.50 \pm 1.97$ & $3.70 \pm 1.81$ \\
\hline
\end{tabular}

Data are presented as the mean \pm SD. $\mathrm{n}=10$. RCOL, Rhodiola crenulata oral liquid; EE, exhaustive exercise; BW, body weight; L, low dose; $\mathrm{M}$, medium dose; $\mathrm{H}$, high dose.

Table IV. Effect of RCOL administration on anti-fatigue indicators in the serum samples and quadriceps femoris tissue of mice.

\begin{tabular}{llccrrr}
\hline Sample & \multicolumn{1}{c}{ Parameter } & Control & EE & RCOL-L & RCOL-M & RCOL-H \\
\hline Serum & CK, U/ml & $0.77 \pm 0.20$ & $2.16 \pm 0.25^{\mathrm{a}}$ & $1.79 \pm 0.08^{\mathrm{b}}$ & $1.55 \pm 0.05^{\mathrm{b}}$ & $1.27 \pm 0.13^{\mathrm{b}}$ \\
Quadriceps femoris & LA, mmol/g prot & $0.51 \pm 0.07$ & $1.29 \pm 0.19^{\mathrm{a}}$ & $1.00 \pm 0.083^{\mathrm{b}}$ & $0.75 \pm 0.07^{\mathrm{b}}$ & $0.69 \pm 0.06^{\mathrm{b}}$ \\
Quadriceps femoris & LDH, U/g prot & $1.26 \pm 0.11$ & $1.98 \pm 0.18^{\mathrm{a}}$ & $1.76 \pm 0.08^{\mathrm{b}}$ & $1.60 \pm 0.12^{\mathrm{b}}$ & $1.55 \pm 0.12^{\mathrm{b}}$ \\
Quadriceps femoris & MDA, nmol/mg prot & $2.95 \pm 0.37$ & $6.03 \pm 0.61^{\mathrm{a}}$ & $4.91 \pm 0.06^{\mathrm{b}}$ & $4.48 \pm 0.14^{\mathrm{b}}$ & $3.93 \pm 0.33^{\mathrm{b}}$ \\
Quadriceps femoris & SOD, U/mg prot & $158.77 \pm 12.95$ & $87.86 \pm 5.21^{\mathrm{a}}$ & $110.82 \pm 5.94^{\mathrm{b}}$ & $121.68 \pm 6.77^{\mathrm{b}}$ & $140.39 \pm 4.14^{\mathrm{b}}$ \\
Quadriceps femoris & CAT, U/mg prot & $18.50 \pm 3.14$ & $4.18 \pm 1.64^{\mathrm{a}}$ & $6.68 \pm 2.25$ & $7.71 \pm 1.90^{\mathrm{c}}$ & $14.44 \pm 3.12^{\mathrm{b}}$ \\
Quadriceps femoris & T-AOC, U/mg prot & $0.67 \pm 0.06$ & $0.28 \pm 0.03^{\mathrm{a}}$ & $0.37 \pm 0.03^{\mathrm{b}}$ & $0.46 \pm 0.04^{\mathrm{b}}$ & $0.55 \pm 0.02^{\mathrm{b}}$ \\
& & & & & &
\end{tabular}

Data are presented as the mean $\pm \mathrm{SD} . \mathrm{n}=8 .{ }^{\mathrm{a}} \mathrm{P}<0.01$ vs. Control; ${ }^{\mathrm{b}} \mathrm{P}<0.01$ and ${ }^{\mathrm{c}} \mathrm{P}<0.05$ vs. EE. RCOL, Rhodiola crenulata oral liquid; EE, exhaustive exercise; L, low dose; M, medium dose; H, high dose; prot, protein; CK, creatine kinase; LA, lactic acid; LDH, lactate dehydrogenase; MDA, malondialdehyde; SOD, superoxide dismutase; CAT, catalase; T-AOC, total antioxidative capability.

and T-AOC were observed in conjunction with significantly reduced $\mathrm{LA}, \mathrm{CK}, \mathrm{LDH}$ and MDA levels in the three different RCOL dosage groups (Table IV). These results suggested that RCOL can relieve fatigue induced by EE in mice, possibly by modulating oxidative stress.

Effect of RCOL administration on the histopathology and ultrastructure of quadriceps femoris in mice. A schematic diagram of the quadriceps femoris muscle structure in mice is presented in Fig. 3A. Morphological analysis of skeletal muscle suggested that there was slight edema in the local muscle interstroma, looser connective tissue arrangement, irregular arrangement and shape of local muscle fibers. Meanwhile, a small amount of muscle fiber area was visibly reduced, and the spacing was slightly widened in the control group. By contrast, RCOL pre-administration appeared to alleviate the above pathological damages (Fig. 3B). Ultrastructural analysis of the mouse quadriceps femoris using TEM further confirmed the protective effect of RCOL pre-administration on EE-induced injury (Fig. 3C). Indeed, compared with the control group, the myofibrils of the quadriceps femoris in the EE group were found to be significantly damaged, disorganized, partially disintegrated and even dissolved, where the A- and $\mathrm{H}$-bands appeared thinner or were missing. The partly or fully disintegrated mitochondrial cristae, mitochondrial swelling or even vacuoles were also visible. In addition, the skeletal muscles of the EE group showed abnormal ultrastructural changes, including disappearance of the I-band, a blurred, disordered arrangement of the Z-disk and serrated corrugation (Fig. 3C1-2). However, other than the changes to the mitochondrial microstructure aforementioned, results from this experiment did not suggest any changes in autophagosomes. Collectively, based on the morphological and ultrastructural characteristics of the skeletal muscle, RCOL pre-administration can protect the skeletal muscle against injury induced by EE.

Effect of RCOL administration on energy production in mice. To evaluate the effect of RCOL on energy production in mice, the contents of liver and muscle glycogen, in addition to the activities of SDH and $\mathrm{Na}^{+}-\mathrm{K}^{+}$-ATPase in the quadriceps femoris were measured by biochemical analysis. Furthermore, CS expression in quadriceps femoris tissue was measured by western blotting. Compared with those in the EE group, the mice in the three RCOL groups exhibited significantly higher liver and muscle glycogen content (Fig. 4A and B), significantly higher CS expression (Fig. 4C and D) and significantly higher SDH (Fig. 4E), and $\mathrm{Na}^{+}-\mathrm{K}^{+}$-ATPase activity (Fig. 4F). Therefore, enhanced ATP production may partially underlie the anti-fatigue effects of RCOL observed in mice following EE.

Effects of RCOL administration on the expression of PINK1/Parkin signaling pathway components. To determine the effects of RCOL on PINK1/Parkin-mediated mitophagy, western blot analysis was performed to measure PINK1, Parkin, LC3-I/LC3-II, p62 and ubiquitin protein expression of mice quadriceps tissue (Fig. 5A-F). To support this, mRNA expression levels of Parkin and PINK1 were measured by RT-qPCR (Fig. 5G and H). Compared with those in the control group, 
A

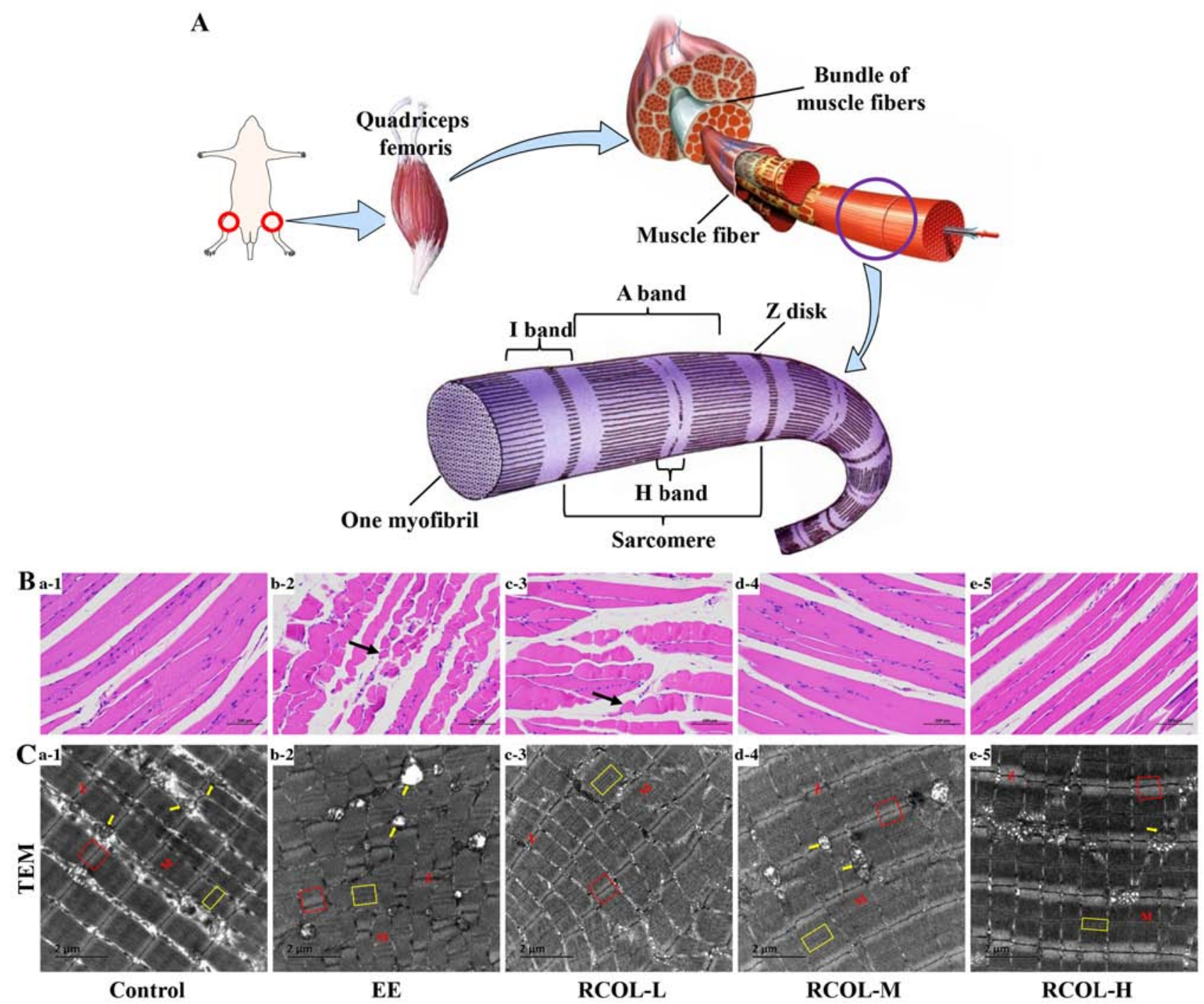

Figure 3. Effects of RCOL administration on the histology and ultrastructure of quadriceps femoris tissue of mice subjected to EE. (A) Schematic diagram of quadriceps femoris of mice tissues. (B) Hematoxylin and eosin staining observed by optical light microscopy. The black arrow indicates areas of reduced muscle fibers. Scale bar, $50 \mu \mathrm{m}$. (C) Ultrastructural analysis of mitochondria by TEM. $\left(\mathrm{C}_{1}\right)$ Compared with the control group, $\left(\mathrm{C}_{2}\right)$ mice in the EE group exhibited more areas of damaged mitochondria. $\left(\mathrm{C}_{3-5}\right)$ Mice in the RCOL groups appeared to have less damaged ultrastructures with a comparable level of uniformity as that observed in the control group. Yellow arrows indicate the location of mitochondria. Red boxes indicate bright zones. The dark zone is located between the $\mathrm{Z}$ and $\mathrm{M}$ lines. Yellow boxes indicate $\mathrm{H}$ zones. Scale bar, $2 \mu \mathrm{m}$. $\mathrm{n}=5$. RCOL, Rhodiola crenulata oral liquid; EE, exhaustive exercise; TEM, transmission electron microscopy; $\mathrm{L}$, low dose; $\mathrm{M}$, medium dose; $\mathrm{H}$, high dose.

mice in the EE group displayed significantly higher expression levels of PINK1, Parkin, LC3-I/LC3-II, p62 and ubiquitin, proteins associated with mitophagy. RCOL pre-administration was found to significantly reverse this effect on the expression of proteins aforementioned. In addition, RT-qPCR results further confirmed the reduced mRNA expression levels of PINK1 and Parkin in the medium and high dose RCOL groups compared with those in the EE group. Altogether, these results suggest that RCOL may protect mice from EE-induced fatigue by inhibiting the expression of mitophagy-related proteins.

\section{Discussion}

RCOL is a tonic containing an abundance of pharmacologically active ingredients and nutrients (22). In the present study, RCOL was found to improve EE-induced skeletal muscle fatigue in mice, increased antioxidant capacity and glycogen synthesis. The anti-fatigue effect of RCOL may be associated with the inhibition of mitophagy through the regulation of the PINK1/Parkin signaling pathway.

Previous studies have suggested that EE can induce damage through the production of reactive oxygen radicals (35-37). The imbalanced reduction-oxidation states in turn lead to muscle weakness and fatigue (35). LA is a metabolite found in skeletal muscle, where the rapid accumulation of LA can cause damage. CK serves an important role in energy transfer, muscle contraction and ATP generation. CK levels have been previously reported to positively correlate with the expression of tissue $\mathrm{LDH}(38,39)$. EE has been found to disrupt the redox state, increase MDA expression and reduce the contents of SOD and CAT, aggravating oxidative damage to the skeletal muscle $(40,41)$. Therefore, LA, CK, LDH, MDA, SOD, CAT and T-AOC were chosen as biomarkers to evaluate the degree of fatigue and oxidation in response to RCOL in skeletal 
A

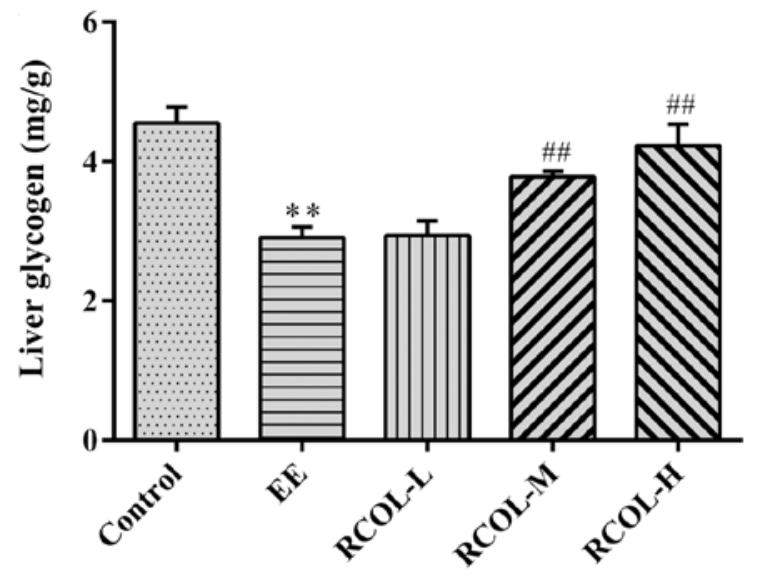

C
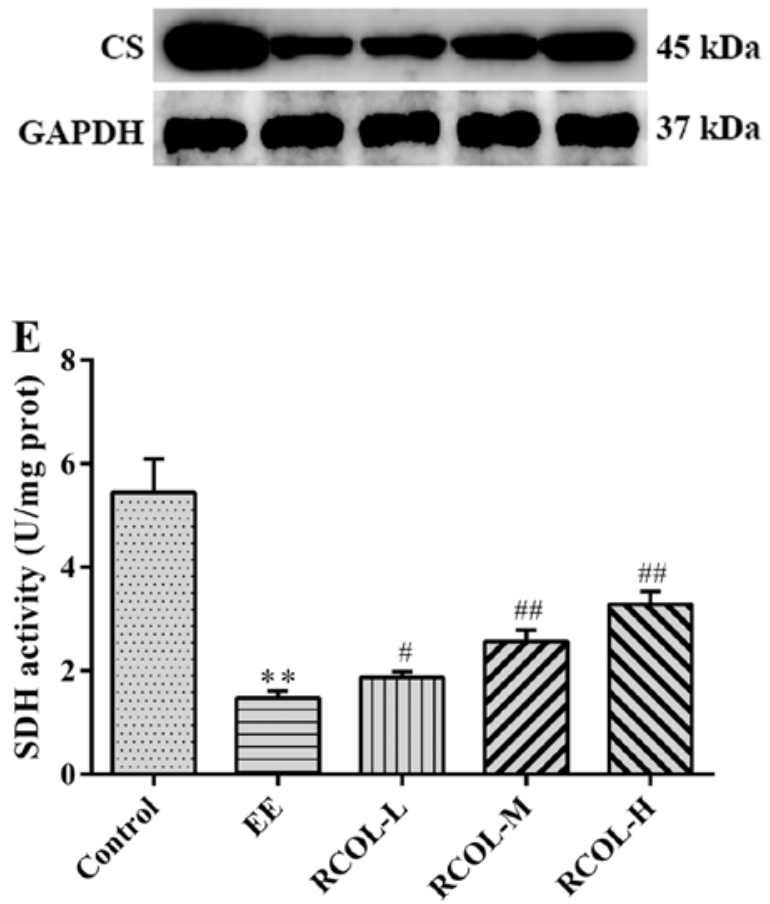

B
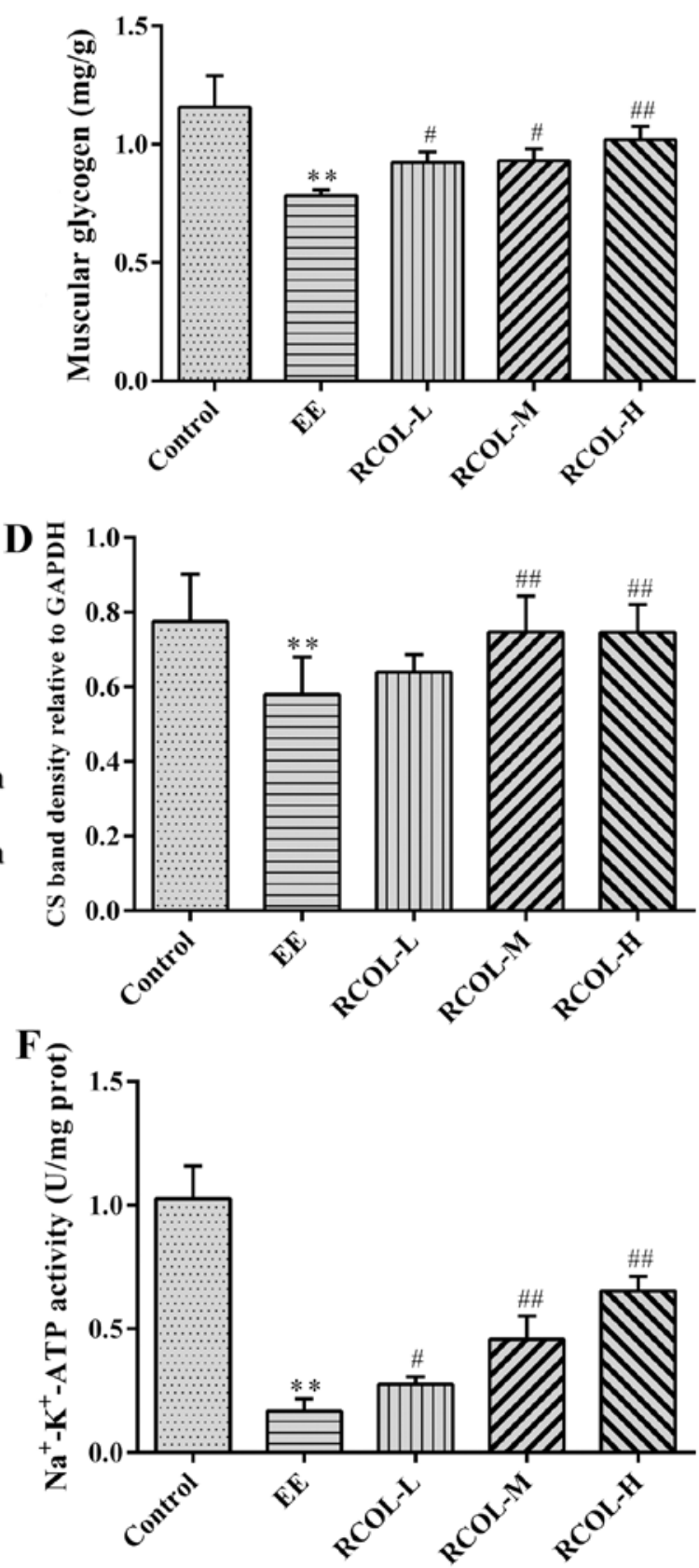

Figure 4. Effects of RCOL administration on energy production in mice. (A) Liver and (B) muscle glycogen content. (C) CS protein expression was measured in quadriceps femoris tissue and (D) quantified by semi-quantitative analysis. (E) SDH activity in quadriceps femoris tissue. (F) Na $\mathrm{N}^{+} \mathrm{K}^{+}$-ATPase activity in quadriceps femoris tissue. Data are presented as the mean $\pm \mathrm{SD} . \mathrm{n}=6 .{ }^{* *} \mathrm{P}<0.01$ vs. Control; ${ }^{*} \mathrm{P}<0.05$ and ${ }^{\# \#} \mathrm{P}<0.01$ vs. EE. RCOL, Rhodiola crenulata oral liquid; EE, exhaustive exercise; L, low dose; $\mathrm{M}$, medium dose; $\mathrm{H}$, high dose; CS, citrate synthase; SDH, succinate dehydrogenase; ATP, adenosine triphosphate; prot, protein.

muscle after EE-induced fatigue. In the present study, RCOL administration was observed to inhibit the levels of LA, CK, LDH and MDA, whilst increasing expression of SOD, CAT and $\mathrm{T}-\mathrm{AOC}$ in the quadriceps femoris tissue, without affecting body weight. These findings suggested that the anti-fatigue properties of RCOL were at least partly associated with its antioxidant effects.

In the present study, at the cellular and microstructural levels, morphological and ultrastructural analysis suggested that EE can disrupt the normal arrangements of skeletal muscle cells, with incomplete and poorly defined sarcolemma. Irregular arrangements of muscle fibers can deteriorate further, as demonstrated by the twisted, broken and dissolved muscle fibers, in addition to myostromal edema (11). It is also worth noting that unaccustomed exercise, in a manner that is dependent on both and intensity, can induce the acute microdisruption of the myofibrils and cytoskeletal structures (42). In addition, broken myofilaments, dilated sarcoplasmic reticula, disruptive 

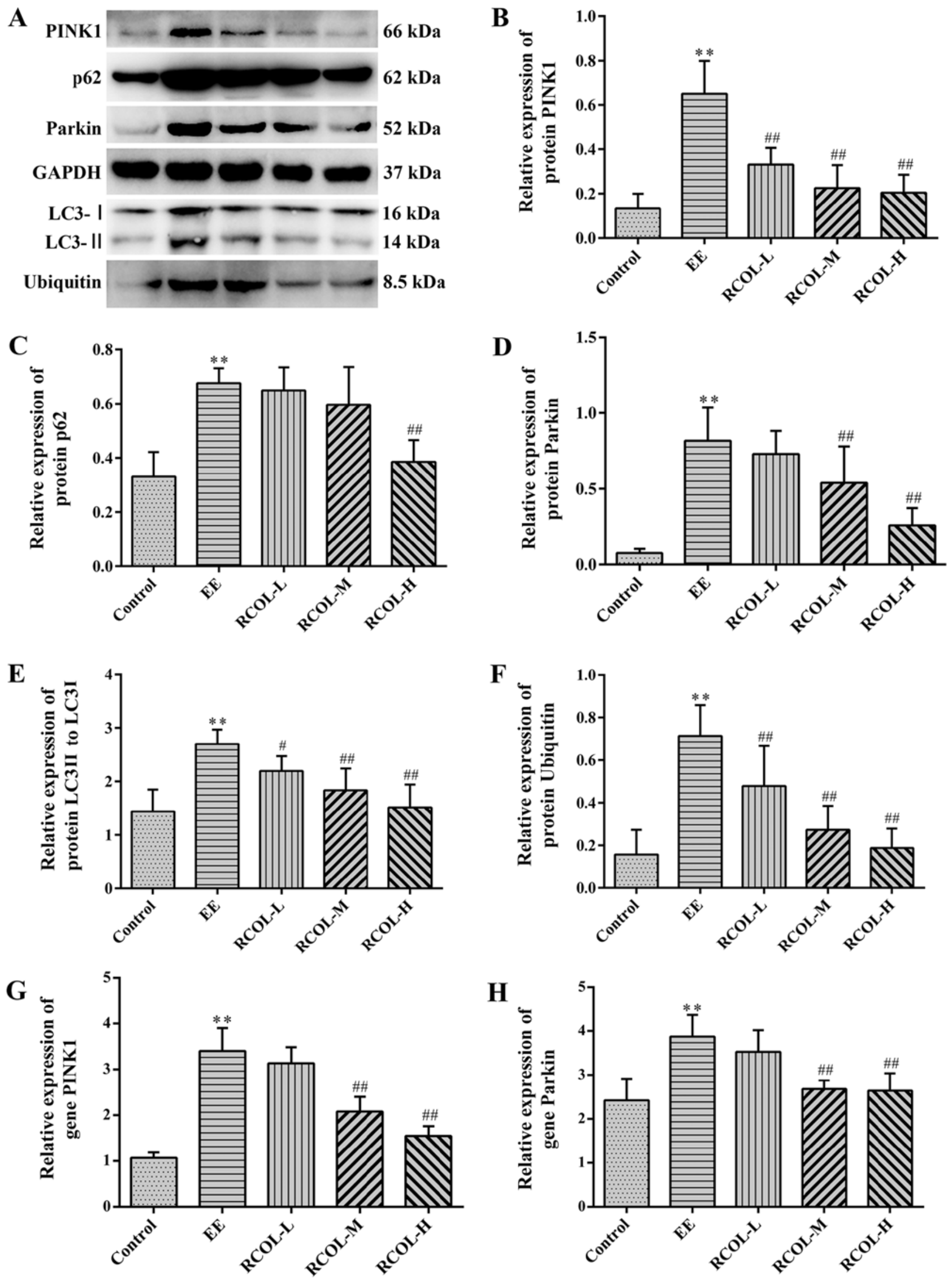

Figure 5. Effects of RCOL administration on the protein and mRNA expression of key PINK1/Parkin signaling pathway components. (A) Representative western blotting images showing the protein expression of PINK1, Parkin, LC3-II/LC3-I, p62 and ubiquitin in mice quadriceps femoris tissues. Semi-quantitative densitometric analysis of (B) PINK1, (C) p62, (D) Parkin, (E) LC3I and (F) ubiquitin. Relative mRNA expression of (G) PINK1 and (H) Parkin, two key proteins associated with mitophagy. Data are presented as the mean $\pm \mathrm{SD} . \mathrm{n}=6 .{ }^{* *} \mathrm{P}<0.01$ vs. Control; ${ }^{*} \mathrm{P}<0.05$ and ${ }^{\# \#} \mathrm{P}<0.01$ vs. EE. RCOL, Rhodiola crenulata oral liquid; EE, exhaustive exercise; L, low dose; M, medium dose; H, high dose; PINK1, PTEN-induced kinase 1; LC3, microtubule associated protein 1 light chain 3. 


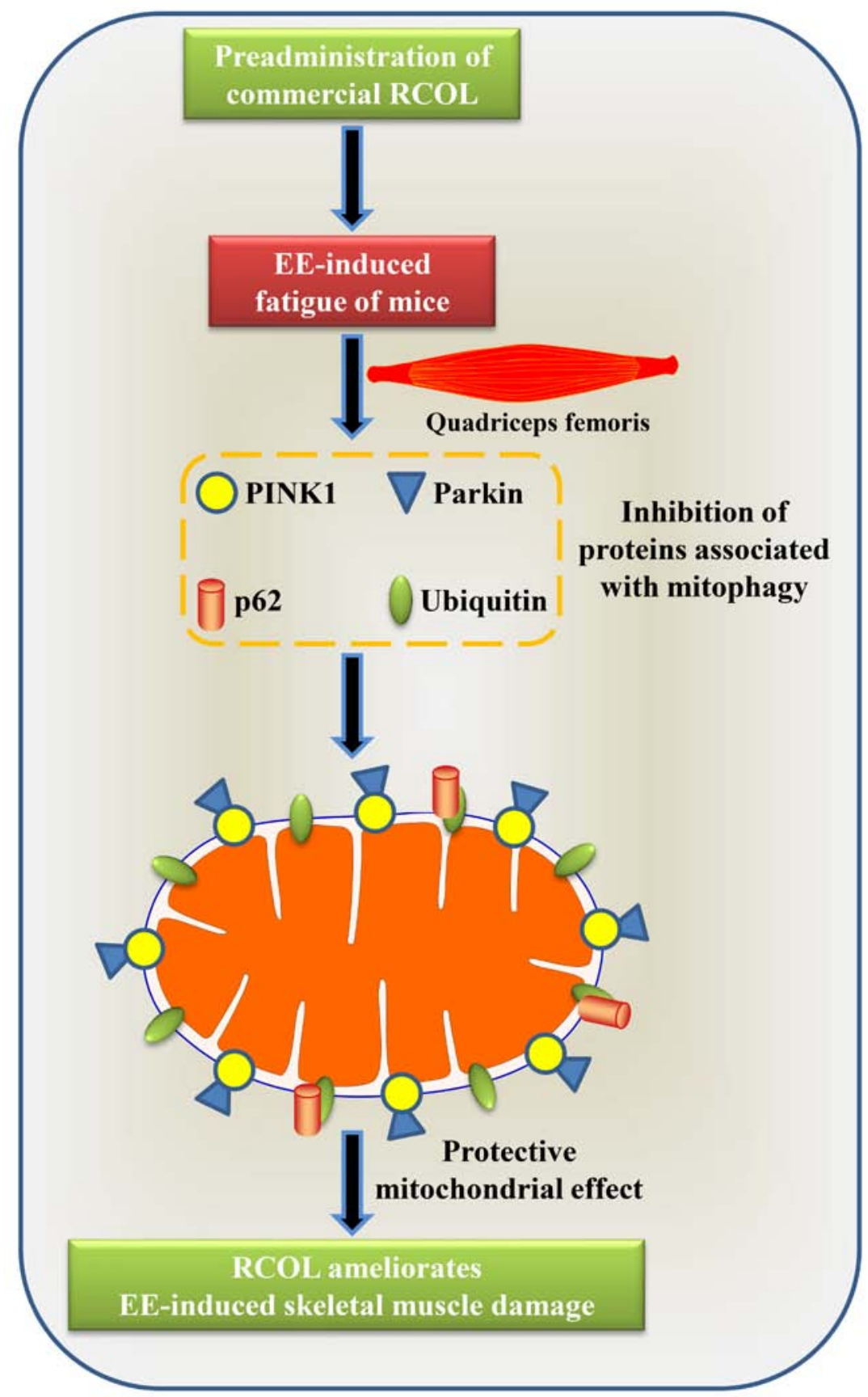

Figure 6. Proposed molecular mechanism for the effect of RCOL pre-administration on improved exercise performance in fatigued mice. RCOL, Rhodiola crenulata oral liquid; EE, exhaustive exercise; PINK1, PTEN-induced kinase 1.

mitochondrial structures, swollen and vacuolated mitochondria were previously observed in EE-induced skeletal muscle damage (12). The present study suggested that RCOL administration mitigated EE-induced skeletal muscle damage, preserved mitochondrial morphology and function, as evidenced by the restoration of the number and area of healthy muscle fibers and the amelioration of ultrastructural damage. However, the results of transmission electron microscopy of skeletal muscle mitochondria in the present study did not provide direct evidence of mitophagy. Future studies should aim to couple investigations of representative markers associated with autophagy, including lysosomes and autophagy-lysosome complexes, with changes to the skeletal muscle fiber and mitochondrial ultrastructure.
CS and SDH are two important catalytic enzymes involved in the tricarboxylic acid cycle. CS and SDH activities are higher in skeletal muscles with more mitochondria, thereby providing more ATP (43). Previous in vitro and in vivo studies suggested that, under normal conditions, Rhodiola crenulata extract (RCE) inhibited hepatic glycogen synthesis, reducing blood glucose levels through activation of the 5'AMP-activated protein kinase (AMPK) signaling pathway (44). By contrast, another previous study reported contrasting results, where RCE treatment increased glycogen synthesis through the AMPK pathway in HepG2 cells incubated under high-glucose conditions (45). Therefore, to determine the effects of RCOL on energy production in mice 
with EE-induced fatigue, glycogen content was evaluated in the liver and quadriceps femoris tissues. RCOL treatment was found to increase glycogen levels in both tissues, possibly owing to enhanced gluconeogenesis process. The activities of $\mathrm{CS}, \mathrm{SDH}$ and $\mathrm{Na}^{+}-\mathrm{K}^{+}$-ATPase in quadriceps femoris were also assessed. Higher $\mathrm{CS}, \mathrm{SDH}$ and $\mathrm{Na}^{+}-\mathrm{K}^{+}$-ATPase activities were confirmed in RCOL-administered mice compared with those in the EE group. Collectively, these findings suggested that RCOL pre-administration increased glycogen content in the liver and muscle tissues, thereby augmenting ATP production. The motor ability and behavioral performance of mice were therefore improved, evidenced by enhanced energy production and improved fatigue-related indicators. Therefore, it may be concluded that RCOL can increase the glycogen content in response to EE. Further in vivo and in vitro studies are required to verify the regulatory effects and mechanisms of RCOL on glycogen synthesis under different conditions, such as diabetes.

Previous studies suggested that autophagy and/or mitophagy were involved in the physiological and pathological homeostasis of mitochondrial quality control in skeletal muscle cell $(13,46,47)$. Parkin, encoded by the Park 2 gene in animals, is a cytoplasmic E3 ubiquitin ligase with broad physiological roles. It is highly expressed in skeletal muscle and other tissues, including the substantia nigra of brain, heart, liver and testis (46). PINK1 belongs to the Ser/Thr protein kinase family which contains a single protein kinase domain and is highly expressed in the mitochondrial outer membrane (MOM) of skeletal muscle. Reduced mitochondrial inner membrane electrochemical gradients, which are initiated by mitochondrial uncouplers or toxins, are required for ATP production. Subsequently, Parkin translocates from the cytosol into the mitochondria under conditions of impaired and imbalanced mitochondrial membrane potentials (13). Accumulation of PINK1 on the MOM, then phosphorylates Parkin on serine 65 to activate the ligase activity of Parkin, resulting in increased mitophagy (48). Additionally, Parkin conjugates ubiquitin chains on proteins located on the MOM, causing signal amplification and recruitment of the autophagosome to initiate mitophagy (13). Therefore, changes in the concentration of PINK1 protein can be used to measure the health status of mitochondria $(49,50)$. PINK1 and Parkin are considered to be the key mediators of mitophagy in removing damaged mitochondria from the cell (51).

SQSTM1/p62 is a ubiquitously expressed scaffold protein that is considered to be a marker of autophagosomes, which serve an essential role in the regulation of mitophagy $(13,52)$.p62 maintains its own intracellular levels by regulating the mitophagy process by directly binding to LC3, forming a LC3/p62 complex (53). Loss of p62 expression results in the inactivation of autophagy and the accumulation of cytoplasmic protein inclusions, thereby contributing to the progression of diseases associated with autophagy deficiency, including cancer and Parkinson's disease (54). In addition, PINK1/parkin-mediated mitophagy has also been found to be associated with ubiquitin and p62 (55). Previous studies suggested that salidroside suppressed bladder cancer cell growth by inhibiting the mechanistic target of the rapamycin (mTOR) pathway and translation initiation, whilst inducing autophagy in tumor cells (56). However, other previous studies have also suggested that salidroside can increase hypoxia and hydrogen peroxide-induced autophagy in pulmonary arterial smooth muscle cells and human umbilical vein endothelial cells through downregulation of mTOR signaling $(57,58)$. Salidroside has also been documented to inhibit autophagy in primary cortical neurons of neonatal Sprague-Dawley rats exposed to glutamate (59) and suppress the mitophagy process in the hippocampal CA3 neurons after chronic hypobaric hypoxia injury (60). Additionally, salidroside alleviated hepatic autophagy in mouse models of hepatic ischemia-reperfusion injury and hepatic fibrosis $(61,62)$. In the present study, western blotting results indicated that RCOL pre-administration inhibited the expression of PINK1, Parkin, LC3, p62 and ubiquitin. Further gene expression analysis conducted by RT-qPCR also suggested that RCOL could downregulate the expression PINK1 and Parkin mRNA. To the best of the authors' knowledge, these results provided the first experimental evidence that RCOL could suppress the expression mitophagy-related proteins in the skeletal muscle following EE induction, including those in the PINK1/Parkin signaling pathway. The proposed molecular mechanism underlying the effects of RCOL pre-administration on alleviating fatigue in mice is presented in Fig. 6.

In conclusion, the present study demonstrated that RCOL pre-administration exerted anti-fatigue effects and improved exercise performance in mice through the regulation of mitophagy-related markers in skeletal muscle including those of the PINK1/Parkin signaling pathway. However, the precise molecular mechanisms underlying the anti-fatigue properties of RCOL require further investigation.

\section{Acknowledgements}

The authors would like to thank Mr. Jiayi Sun, research assistant at The Innovative Institute of Chinese Medicine and Pharmacy, Chengdu University of Traditional Chinese Medicine, Chengdu, China, for providing technical guidance on hematoxylin and eosin staining, as well as RT-qPCR assays during the present study.

\section{Funding}

The present study was supported by The National Key R\&D Program of China (grant no. 2017YFC1703904), The Major Science and Technology Project of Sichuan Science and Technology Department (grant no. 19SYXHZ0095), The National Natural Science Foundation of China (grant nos. 81773974 and 81203000), The Science \& Technology Department of Sichuan Province (grant no. 2018JY0467), Sichuan Science and Technology Program (grant no. 2019YJ0480), and The First-Class Interdisciplinary Project of Chengdu University of Traditional Chinese Medicine (grant no. CZYJC-1903).

\section{Availability of data and materials}

The datasets used and/or analyzed during the current study are available from the corresponding author on reasonable request.

\section{Authors' contributions}

$\mathrm{XM}, \mathrm{JZ}$ and Y Hu provided financial support for the research, designed the study, supervised the research group, revised 
drafts and gave approval for the final version to be published. Y Hou, XW, XA, HW, YT, and XC performed the experiments. YZ, Y Hu and XL analyzed and interpreted the data. YH wrote the manuscript. All authors approved the final version of the manuscript.

\section{Ethics approval and consent to participate}

The present study was approved by The Animal Research Ethics Committee of Chengdu University of Traditional Chinese Medicine. All experimental protocols were performed in accordance with the Animal Care Guidelines, conforming to the Health Guide for the Care and Use of Laboratory Animals.

\section{Patient consent for publication}

Not applicable.

\section{Competing interests}

The authors declare that they have no competing interests.

\section{References}

1. O'Sullivan K, O'Sullivan PB and Gabbett TJ: Pain and fatigue in sport: Are they so different? Br J Sports Med 52: 555-556, 2018.

2. Kaufman JL, Mina R, Jakubowiak AJ, Zimmerman TL, Wolf JJ, Lewis C,GleasonC,SharpC,Martin T,HeffnerLT, et al:Combining carfilzomib and panobinostat to treat relapsed/refractory multiple myeloma: Results of a multiple myeloma research consortium Phase I Study. Blood Cancer J 9: 3, 2019.

3. Witlox L, Hiensch AE, Velthuis MJ, Steins Bisschop CN, Los M, Erdkamp FL, Bloemendal HJ, Verhaar M, Ten Bokkel Huinink D, van der Wall $\mathrm{E}$, et al: Four-year effects of exercise on fatigue and physical activity in patients with cancer. BMC Med 16: 86 , 2018.

4. Fuller JT, Hartland MC, Maloney LT and Davison K: Therapeutic effects of aerobic and resistance exercises for cancer survivors: A systematic review of meta-analyses of clinical trials. Br J Sports Med 52: 1311, 2018.

5. Cramp F and Byron-Daniel J: Exercise for the management of cancer-related fatigue in adults. Cochrane Database Syst Rev 11: CD006145, 2012.

6. Pilutti LA, Greenlee TA, Motl RW, Nickrent MS and Petruzzello SJ: Effects of exercise training on fatigue in multiple sclerosis: A meta-analysis. Psychosom Med 75: 575-580, 2013.

7. Fu T, Xu Z, Liu L, Guo Q, Wu H, Liang X, Zhou D, Xiao L, Liu L, Liu Y, et al: Mitophagy directs muscle-adipose crosstalk to alleviate dietary obesity. Cell Rep 23: 1357-1372, 2018.

8. Peker N, Donipadi V, Sharma M, McFarlane C and Kambadur R: Loss of parkin impairs mitochondrial function and leads to muscle atrophy. Am J Physiol Cell Physiol 315: C164-C185, 2018.

9. Brooks GA: Lactate as a fulcrum of metabolism. Redox Biol 35: 101454, 2020.

10. Barbalho SM, Flato UAP, Tofano RJ, Goulart RA, Guiguer EL, Detregiachi CRP, Buchaim DV, Araújo AC, Buchaim RL, Reina FTR, et al: Physical exercise and myokines: Relationships with sarcopenia and cardiovascular complications. Int J Mol Sci 21: 3607, 2020.

11. Lambert M, Bastide B and Cieniewski-Bernard C: Involvement of O-GlcNAcylation in the skeletal muscle physiology and physiopathology: Focus on muscle metabolism. Front Endocrinol 9: 578, 2018.

12. Arribat Y, Broskey NT, Greggio C, Boutant M, Conde Alonso S, Kulkarni SS, Lagarrigue S, Carnero EA, Besson C, Cantó C and Amati F: Distinct patterns of skeletal muscle mitochondria fusion, fission and mitophagy upon duration of exercise training. Acta Physiol (Oxf) 225: e13179, 2019.

13. Wang X, Liu Z, Fan F, Hou Y, Yang H, Meng X, Zhang Y and Ren F: Microfluidic chip and its application in autophagy detection. TrAC Trends Analyt Chem 117: 300-315, 2019.
14. Chen HI, Ou HC, Chen CY, Yu SH, Cheng SM, Wu XB and Lee SD: Rhodiola crenulata neuroprotective effect of in D-galactose-induced aging model. Am J Chin Med 48: 373-390, 2020.

15. Wang X, Hou Y, Li Q, Li X, Wang W, Ai X, Kuang T, Chen X, Zhang Y, Zhang J, et al: Rhodiola crenulata attenuates apoptosis and mitochondrial energy metabolism disorder in rats with hypobaric hypoxia-induced brain injury by regulating the HIF-1 $\alpha /$ microRNA 210/ISCU1/2(COX10) signaling pathway. J Ethnopharmacol 241: 111801, 2019.

16. Booker A, Zhai L, Gkouva C, Li S and Heinrich M: From traditional resource to global commodities:-A comparison of rhodiola species using NMR spectroscopy-metabolomics and HPTLC. Front Pharmacol 7: 254, 2016.

17. Sellami M, Slimeni O, Pokrywka A, Kuvačić G, D Hayes L, Milic M and Padulo J: Herbal medicine for sports: A review. J Int Soc Sports Nutr 15: 14, 2018

18. Zhang YZ, Zhu RW, Zhong DL and Zhang JQ: Nunataks or massif de refuge? A phylogeographic study of Rhodiola crenulata (Crassulaceae) on the world's highest sky islands. BMC Evol Biol 18: 154, 2018.

19. Torrens-Spence MP, Pluskal T, Li FS, Carballo V and Weng JK: Complete pathway elucidation and heterologous reconstitution of rhodiola salidroside biosynthesis. Mol Plant 11: 205-217, 2018.

20. Chang PK, Yen IC, Tsai WC, Chang TC and Lee SY: Protective effects of extract on hypoxia-induced endothelial damage via regulation of AMPK and ERK pathways. Int J Mol Sci 19: 2286, 2018.

21. Zhang Y and Zhao Q: Salidroside attenuates interleukin-1 $\beta$ induced inflammation in human osteoarthritis chondrocytes. J Cell Biochem 30: 1002, 2018.

22. Liu Y, Tang H, Liu X, Chen H, Feng N, Zhang J, Wang C, Qiu M, Yang J and Zhou X: Frontline science: Reprogramming COX-2, 5-LOX, and CYP4A-mediated arachidonic acid metabolism in macrophages by salidroside alleviates gouty arthritis. J Leukoc Biol 105: 11-24, 2019.

23. Wang JM, Qu ZQ, Wu JL, Chung P and Zeng YS: Mitochondrial protective and anti-apoptotic effects of extract on hippocampal neurons in a rat model of alzheimer's disease. Neural Regen Res 12: 2025-2034, 2017.

24. Li FJ, Liu Y, Yuan Y, Yang B, Liu ZM and Huang LQ: Molecular interaction studies of acetylcholinesterase with potential acetylcholinesterase inhibitors from the root of Rhodiola crenulata using molecular docking and isothermal titration calorimetry methods. Int J Biol Macromol 104: 527-532, 2017.

25. Wu H, Chen W, Zhao F, Zhou Q, Reinach PS, Deng L, Ma L, Luo S, Srinivasalu N, Pan M, et al: Scleral hypoxia is a target for myopia control. Proc Natl Acad Sci USA 115: E7091-E7100, 2018.

26. Lin KT, Chang TC, Lai FY, Lin CS, Chao HL and Lee SY: Rhodiola crenulata attenuates $\gamma$-ray induced cellular injury via modulation of oxidative stress in human skin cells. Am J Chin Med 46: 175-190, 2018.

27. Bassa LM, Jacobs C, Gregory K, Henchey E, Ser-Dolansky J and Schneider SS: Rhodiola crenulata induces an early estrogenic response and reduces proliferation and tumorsphere formation over time in MCF7 breast cancer cells. Phytomedicine 23: 87-94, 2016.

28. Couto M: Laboratory guidelines for animal care. Methods Mol Biol 770: 579-599, 2011

29. Zhao CY, Jia GF, He ZJ, Luo QF, Fan G, Zhang Y and Zhao WJ: Effect of fertilization combinations of nitrogen, phosphorus, and potassium on four phenolic compounds of cultivated Rhodiola crenulata. Zhongguo Zhong Yao Za Zhi 43: 1812-1817, 2018 (In Chinese).

30. Hu Y, Zhang J, Zhang Y, Wang P and Meng X: Metabonomic study on fatigue elimination of exhaustive exercise mouse by rhodiola based on UFLC-Q-TOF. World Science and Technology/Modernization of Traditional Chinese Medicine and Materia Medica 17: 2209-2214, 2015 (In Chinese).

31. Hou Y, Wang X, Chen X, Zhang J, Ai X, Liang Y, Yu Y, Zhang Y, Meng X, Kuang T and Hu Y: Establishment and evaluation of a simulated high-altitude hypoxic brain injury model in SD rats. Mol Med Rep 19: 2758-2766, 2019.

32. Hou Y, Qieni X, Li N, Bai J, Li R, Gongbao D, Liang Y, Fan F, Wencheng D, Wang Z, et al: Longzhibu disease and its therapeutic effects by traditional Tibetan medicine: Ershi-wei chenxiang pills. J Ethnopharmacol 249: 112426, 2020.

33. Moore TM, Zhou Z, Cohn W, Norheim F, Lin AJ, Kalajian N, Strumwasser AR, Cory K, Whitney K, Ho T, et al: The impact of exercise on mitochondrial dynamics and the role of Drp1 in exercise performance and training adaptations in skeletal muscle. Mol Metab 21: 51-67, 2019. 
34. Livak KJ and Schmittgen TD: Analysis of relative gene expression data using real-time quantitative PCR and the 2(-Delta Delta C(T)) method. Methods 25: 402-408, 2001.

35. Liu R, Wu L, Du Q, Ren JW, Chen QH, Li D, Mao RX, Liu XR and Li Y: Small molecule oligopeptides isolated from walnut (Juglans regia L.) and their anti-fatigue effects in mice. Molecules 24: 45, 2018.

36. Lekhi C, Gupta PH and Singh B: Influence of exercise on oxidant stress products in elite Indian cyclists. Br J Sports Med 41: 691-693, 2007.

37. McAnulty SR, McAnulty LS, Nieman DC, Morrow JD, Shooter LA, Holmes S, Heward C and Henson DA: Effect of alpha-tocopherol supplementation on plasma homocysteine and oxidative stress in highly trained athletes before and after exhaustive exercise. J Nutr Biochem 16: 530-537, 2005.

38. Nonaka K, Ozaki Y, Ito K, Sakita M, Une S and Akiyama J: Endurance exercise increases the protein levels of PGC-1 $\alpha$ and respiratory chain complexes in mouse skeletal muscle during atorvastatin administration. J Physiol Sci 69: 327-333, 2019.

39. Assunção Carvalho LC, de Freitas MC, Silva AS, Biasoto AC, Martins MD, de Moura RC, Brito AK, Silva AS, Ribeiro SL, Rossi FE and Santos MA: Nectar supplementation reduced biomarkers of oxidative stress, muscle damage, and improved psychological response in highly trained young handball players. Front Physiol 9: 1508, 2018.

40. Vollaard NB, Shearman JP and Cooper CE: Exercise-induced oxidative stress: Myths, realities and physiological relevance. Sports Med 35: 1045-1062, 2005.

41. Powers SK and Jackson MJ: Exercise-induced oxidative stress: Cellular mechanisms and impact on muscle force production. Physiol Rev 88: 1243-1276, 2008.

42. Minetto MA, Giannini A, McConnell R, Busso C and Massazza G: Effects of exercise on skeletal muscles and tendons. Curr Opin Endocrine Metabolic Res 9: 90-95, 2019.

43. Ratkevicius A, Carroll AM, Kilikevicius A, Venckunas T, McDermott KT, Gray SR, Wackerhage H and Lionikas A: H55N polymorphism as a likely cause of variation in citrate synthase activity of mouse skeletal muscle. Physiol Genomics 42: 96-102, 2010.

44. Lee SY, Lai FY, Shi LS, Chou YC, Yen IC and Chang TC: Rhodiola crenulata extract suppresses hepatic gluconeogenesis via activation of the AMPK pathway. Phytomedicine 22: 477-486, 2015

45. Lin KT, Hsu SW, Lai FY, Chang TC, Shi LS and Lee SY: Rhodiola crenulata extract regulates hepatic glycogen and lipid metabolism via activation of the AMPK pathway. BMC Comp Altern Med 16: 127, 2016.

46. Gouspillou G, Godin R, Piquereau J, Picard M, Mofarrahi M, Mathew J, Purves-Smith FM, Sgarioto N, Hepple RT, Burelle Y and Hussain SN: Protective role of Parkin in skeletal muscle contractile and mitochondrial function. J Physiol 596: 2565-2579, 2018.

47. Chen CC, Erlich AT and Hood DA: Role of parkin and endurance training on mitochondrial turnover in skeletal muscle. Skelet Muscle 8: 10, 2018.

48. Youle RJ and Narendra DP: Mechanisms of mitophagy. Nat Rev Mol Cell Biol 12: 9-14, 2011

49. Narendra DP, Jin SM, Tanaka A, Suen DF, Gautier CA, Shen J, Cookson MR and Youle RJ: PINK1 is selectively stabilized on impaired mitochondria to activate parkin. PLoS Biol 8: e1000298, 2010
50. Matsuda N, Sato S, Shiba K, Okatsu K, Saisho K, Gautier CA, Sou YS, Saiki S, Kawajiri S, Sato F, et al: PINK1 stabilized by mitochondrial depolarization recruits parkin to damaged mitochondria and activates latent Parkin for mitophagy. J Cell Biol 189: 211-221, 2010.

51. Botella J, Saner N and Granata C: Guardian of mitochondrial function: An expanded role of parkin in skeletal muscle. J Physiol 596: 6139-6140, 2018.

52. Moscat J and Diaz-Meco MT: p62 at the crossroads of autophagy, apoptosis, and cancer. Cell 137: 1001-1004, 2009.

53. Ichimura Y, Kumanomidou T, Sou YS, Mizushima T, Ezaki J, Ueno T, Kominami E, Yamane T, Tanaka K and Komatsu M: Structural basis for sorting mechanism of p62 in selective autophagy. J Biol Chem 283: 22847-22857, 2008.

54. Komatsu M, Waguri S, Koike M, Sou YS, Ueno T, Hara T, Mizushima N, Iwata J, Ezaki J, Murata S, et al: Homeostatic levels of p62 control cytoplasmic inclusion body formation in autophagy-deficient mice. Cell 131: 1149-1163, 2007.

55. Geisler S, Holmström KM, Skujat D, Fiesel FC, Rothfuss OC, Kahle PJ and Springer W: PINK1/parkin-mediated mitophagy is dependent on VDAC1 and p62/SQSTM1. Nat Cell Biol 12: 119-131, 2010.

56. Liu Z, Li X, Simoneau AR, Jafari M and Zi X: Rhodiola rosea extracts and salidroside decrease the growth of bladder cancer cell lines via inhibition of the mTOR pathway and induction of autophagy. Mol Carcinog 51: 257-267, 2012.

57. Gui D, Cui Z, Zhang L, Yu C, Yao D, Xu M, Chen M, Wu P, Li G, Wang L and Huang X: Salidroside attenuates hypoxia-induced pulmonary arterial smooth muscle cell proliferation and apoptosis resistance by upregulating autophagy through the AMPK-mTOR-ULK1 pathway. BMC Pulm Med 17: 191, 2017.

58. Zheng XT, Wu ZH, Wei Y, Dai JJ, Yu GF, Yuan F and Ye LC: Induction of autophagy by salidroside through the AMPK-mTOR pathway protects vascular endothelial cells from oxidative stress-induced apoptosis. Mol Cell Biochem 425: 125-138, 2017

59. Yin WY, Ye Q, Huang HJ, Xia NG, Chen YY, Zhang Y and Qu QM: Salidroside protects cortical neurons against glutamate-induced cytotoxicity by inhibiting autophagy. Mol Cell Biochem 419: 53-64, 2016.

60. Biswal S, Barhwal KK, Das D, Dhingra R, Dhingra N, Nag TC and Hota SK: Salidroside mediated stabilization of $\mathrm{Bcl}-\mathrm{x}_{\mathrm{L}}$ prevents mitophagy in CA3 hippocampal neurons during hypoxia. Neurobiol Dis 116: 39-52, 2018.

61. Feng J, Chen K, Xia Y, Wu L, Li J, Li S, Wang W, Lu X, Liu T and Guo C: Salidroside ameliorates autophagy and activation of hepatic stellate cells in mice via NF- $\kappa \mathrm{B}$ and TGF- $\beta 1 / \mathrm{Smad} 3$ pathways. Drug Des Devel Ther 12: 1837-1853, 2018

62. Feng J, Zhang Q, Mo W, Wu L, Li S, Li J, Liu T, Xu S, Fan X and Guo C: Salidroside pretreatment attenuates apoptosis and autophagy during hepatic ischemia-reperfusion injury by inhibiting the mitogen-activated protein kinase pathway in mice. Drug Des Devel Ther 11: 1989-2006, 2017.

This work is licensed under a Creative Commons Attribution-NonCommercial-NoDerivatives 4.0 International (CC BY-NC-ND 4.0) License. 